\title{
Esophageal human $\beta$-defensin expression in eosinophilic esophagitis
}

\author{
Shauna Schroeder ${ }^{1-4}$, Zachary D. Robinson ${ }^{1,2}$, Joanne C. Masterson ${ }^{1-3}$, Lindsay Hosford ${ }^{1,2}$, Wendy Moore ${ }^{1-3}$, Zhaoxing Pan ${ }^{1,3}$, \\ Rachel Harris ${ }^{1,2}$, Rhonda F. Souza ${ }^{5}$, Stuart Jon Spechler ${ }^{5}$, Sophie A. Fillon ${ }^{1-3}$ and Glenn T. Furuta ${ }^{1-3,6}$
}

BACKGROUND: Defensins are antimicrobial peptides expressed on mucosal surfaces that contribute to maintaining intestinal homeostasis by providing innate defense mechanisms for the epithelia. Defensin expression is altered in a number of diseases that affect mucosal surfaces, such as atopic dermatitis, allergic rhinitis, and inflammatory bowel disease. Similar to atopic dermatitis, eosinophilic esophagitis (EOE) is a chronic disease in which the squamous epithelial surface is affected by a similar $\mathrm{T}_{H} 2$ microenvironment and eosinophilpredominant inflammation. Therefore, we hypothesized that defensin expression would be decreased in EoE.

METHODS: To address this, we measured defensin expression in vitro in cell lines derived from patients with EoE (EoE1-T) or gastroesophageal reflux disease (GERD) (NES-G4T cells) and ex vivo in esophageal mucosal biopsy samples from children with EoE or GERD and control children without esophageal disease.

RESULTS: Interleukin-5 induced a decrease in human $\beta$-defensin (hBD) -1 and hBD3 expression in EoE1-T but not in NES-G4T cells. Compared with esophageal biopsy specimens from GERD and control children, specimens from EoE pediatric patients revealed a significant decrease in mRNA and protein expression for hBD1 and hBD3.

CONCLUSION: Diminished expression of hBD1 and hBD3 may make the esophageal epithelium more susceptible to the development and/or perpetuation of EoE.

T he esophageal epithelium is continuously bathed with dietary proteins, environmental allergens, and microbes. In this regard, the stratified squamous epithelium provides a physical barrier to the luminal microenvironment. Secreted bicarbonate, mucus, and antimicrobial peptides form integral parts of the innate esophageal mucosal defense mechanisms (1). Groups of these endogenous antimicrobials are termed defensins, a family of cationic proteins with broad activity against Gram-positive and Gram-negative bacteria, fungi, and enveloped viruses. The two major functions of defensins are to protect from pathogenic invasion of microbes and govern the commensal microbiota $(2,3)$. Human $\beta$-defensin $(\mathrm{hBD})-1$ is constitutively expressed, whereas others are induced by infectious or inflammatory stimuli (4-6).

An increasing body of data demonstrates that dysregulation or deficiencies in epithelial defensin expression may predispose the mucosal surface to microbial invasion and disease exacerbation. For instance, patients with atopic dermatitis, a chronic disease characterized by infiltration of the dermis with eosinophils, have deficiencies in $\mathrm{hBD} 2, \mathrm{hBD} 3$, and cathelicidin (LL-37), as well as single-nucleotide polymorphisms in hBD1 $(7-14)$.

Eosinophilic esophagitis (EoE) is a chronic inflammatory disease of the esophagus mediated by an immune/allergen response leading to eosinophil accumulation in the esophageal mucosa. Symptoms frequently mimic those of gastroesophageal reflux disease (GERD), but the diseases appear to be distinct in their gene expression, response to therapy, and association with allergies $(15,16)$. To date, pathogenic mechanisms are not certain, but genetic perturbations in eotaxin-3, thymic stromal lymphopoietin, and filaggrin have been identified and may contribute (17). Because EoE has been considered an atopic disease, similar to atopic dermatitis because of its predilection to the squamous epithelia, atopic etiology, and eosinophilic nature, we hypothesized that defensin expression was diminished in the epithelia affected by EoE, and this may contribute to the initiation and/or perpetuation of esophageal inflammation.

\section{RESULTS}

\section{Expression of hBD Is Decreased in Human EoE Cells}

To determine whether there was a rationale for addressing our hypothesis, we first examined whether esophageal epithelial cells express defensins in vitro using previously described cell lines derived from adults with EoE (EoE1-T) or GERD (NESG4T) $(18,19)$. Both cell lines expressed hBD1, hBD2, and hBD3 mRNA at baseline. Unstimulated confluent monolayer cultures of EoE1-T cells demonstrated significantly lower expression of

\footnotetext{
The first two authors contributed equally to this work.

'Department of Pediatrics, Gastrointestinal Eosinophilic Diseases Program, University of Colorado School of Medicine, Aurora, Colorado; ${ }^{2}$ Mucosal Inflammation Program,

University of Colorado School of Medicine, Aurora, Colorado; ${ }^{3}$ Digestive Health Institute, Section of Pediatric Gastroenterology, Hepatology, and Nutrition, Children's Hospital Colorado, Aurora, Colorado; ${ }^{4}$ Phoenix Children's Hospital, Phoenix, Arizona; ${ }^{5}$ Department of Medicine, VA North Texas Health Care System-Dallas and University of Texas Southwestern Medical, Dallas, Texas; ${ }^{6}$ Department of Pediatrics, National Jewish Health, Denver, Colorado. Correspondence: Glenn T. Furuta (glenn.furuta@childrenscolorado.org) 
hBD1 and hBD3 compared with NES-G4T cells (60\% decrease in hBD $1, P<0.001 ; 40 \%$ decrease in hBD3, $P<0.01$; EoE1-T compared with NES-G4T). There was no significant change in the expression of hBD2 in EoE1-T compared with NES-G4T cells (Figure 1).

To simulate an EoE microenvironment, EoE1-T and NESG4T cells were incubated with interleukin (IL)-5, an important eosinophil growth factor elevated in mucosal biopsies of patients with EoE (20), and the expression of hBD1 and hBD3 was measured. Stimulation of cells with IL-5 led to a decrease in defensin mRNA expression of hBD1 and hBD3 in EoE1-T but not NES-G4T cell lines (Figure 2).

Expression levels of other antimicrobial peptides including LL-37, hBD2, hBD4, and hBD5 were not shown to differ either at baseline or following stimulation comparing EoE1-T and NES-G4T cell lines and thus were not examined further.
Because our in vitro findings identified changes in only hBD1 and hBD3, we only examined expression of these defensins in esophageal biopsy studies as reported below.

\section{Defensin Expression Is Decreased in Esophageal Mucosa From EoE Subjects}

We next measured defensin expression in human esophageal biopsies obtained from well-characterized pediatric subjects (Table 1). Included in the study were 11 control subjects without esophageal disease (mean age: $11.7 \pm 4.5$ y, 55\% male, $90 \%$ Caucasian), 9 GERD subjects (mean age: $11.9 \pm 6.4$ y, 60\% male, $80 \%$ Caucasian, $60 \%$ on proton pump inhibitor therapy), 9 subjects with untreated EoE (mean age: $10.1 \pm 6.1$ y, 55\% male, $88 \%$ Caucasian), and 13 subjects with EoE who had received treatment (mean age: $9.0 \pm 3.5$ y, 46\% male, 92\% Caucasian). Four of the 13 EoE-treated subjects continued to have active inflammation.
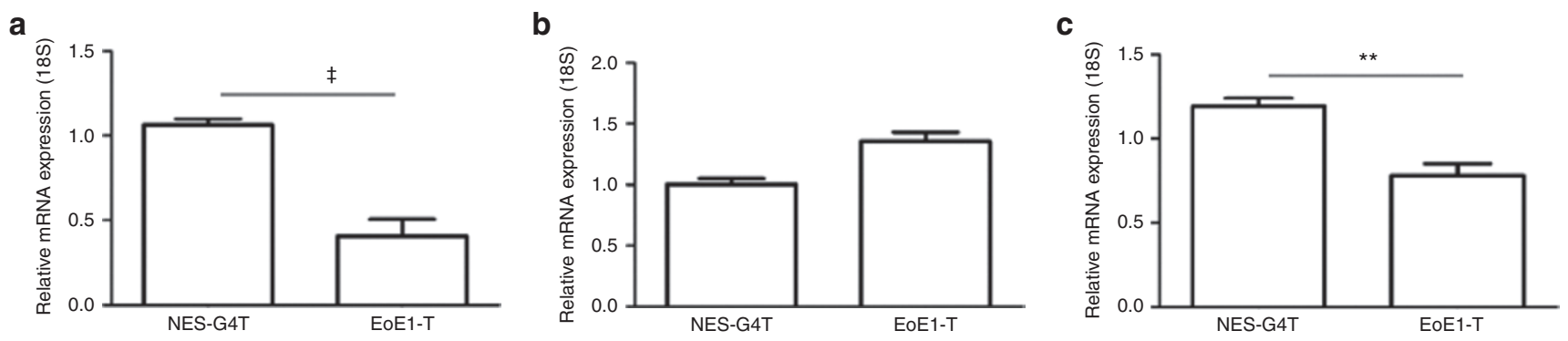

Figure 1. mRNA expression of human $\beta$-defensins in human esophageal squamous epithelial cells. Quantitative real-time PCR was performed using RNA isolated from NES-G4T (GERD cells) and EoE1-T (EoE cells). (a) Human $\beta$-defensin 1, ${ }^{\ddagger} P<0.001$. (b) Human $\beta$-defensin 2. (c) Human $\beta$-defensin 3, ${ }^{* *} P<0.01$. Relative expression compared with 18S. Results are representative of four separate experiments. EoE, eosinophilic esophagitis; GERD, gastroesophageal reflux disease.

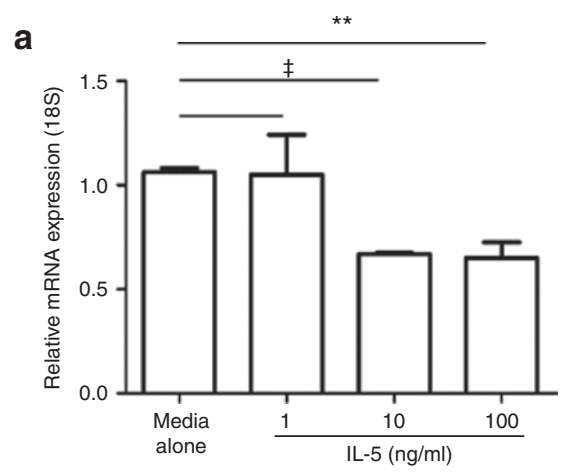

b

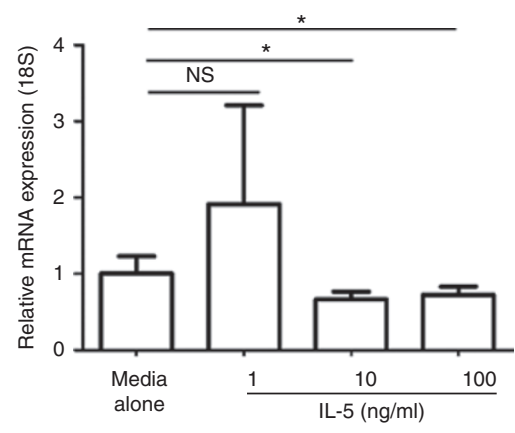

d

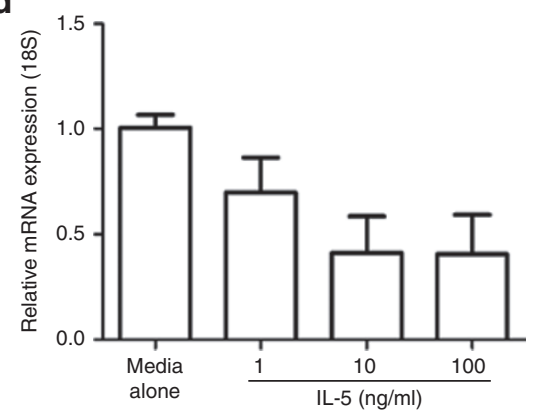

c

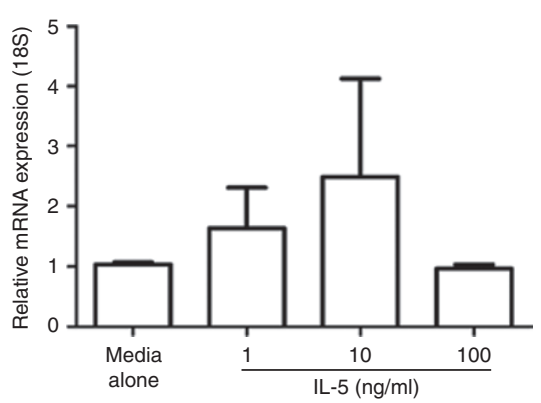

Figure 2. In vitro culture experiment of human esophageal squamous epithelial cells, EoE1-T, and NES-G4T with increasing concentrations of IL-5 (ng/ml). (a) EoE1-T-hBD1, (b) EoE1-T-hBD3, (c) NES-G4T-hBD1, and (d) NES-G4T-hBD3. Changes in mRNA expression are shown relative to baseline expression in each cell line. ${ }^{*} P<0.05 ;{ }^{* *} P<0.01 ;{ }^{\ddagger} P<0.001$; NS, not significant. Relative expression compared with $18 \mathrm{~S}$. Results are representative of three separate experiments. EoE, eosinophilic esophagitis; hBD, human $\beta$-defensin; IL, interleukin. 
Table 1. Description of 38 patients in four experimental groups

\begin{tabular}{|c|c|c|c|c|}
\hline Diagnosis & $\begin{array}{l}\text { Eosinophils } \\
\text { per HPF }\end{array}$ & Age (y) & Atopy & Treatment \\
\hline \multicolumn{5}{|l|}{ EoE } \\
\hline 1 & $>100$ & 4 & $\mathrm{Y}$ & None \\
\hline 2 & $>100$ & 4 & $\mathrm{Y}$ & None \\
\hline 3 & 90 & 5 & $\mathrm{Y}$ & None \\
\hline 4 & 30 & 12 & $\mathrm{Y}$ & None \\
\hline 5 & 25 & 19 & $\mathrm{~N}$ & None \\
\hline 6 & 20 & 19 & $\mathrm{~N}$ & None \\
\hline 7 & 19 & 12 & $Y$ & None \\
\hline 8 & 15 & 11 & $\mathrm{Y}$ & None \\
\hline 9 & 15 & 5 & $\mathrm{~N}$ & None \\
\hline \multicolumn{5}{|l|}{ Treated EoE } \\
\hline 1 & 64 & 12 & $\mathrm{Y}$ & $\begin{array}{l}\text { Topical } \\
\text { glucocorticoid }\end{array}$ \\
\hline 2 & 25 & 4 & Y & $\begin{array}{l}\text { Topical } \\
\text { glucocorticoid/ } \\
\text { diet/PPI }\end{array}$ \\
\hline 3 & 23 & 7 & $\mathrm{~N}$ & $\begin{array}{l}\text { Topical } \\
\text { glucocorticoid }\end{array}$ \\
\hline 4 & 22 & 13 & $\mathrm{~N}$ & $\begin{array}{l}\text { Topical } \\
\text { glucocorticoid/diet }\end{array}$ \\
\hline 5 & 15 & 8 & $\mathrm{Y}$ & $\begin{array}{l}\text { Topical } \\
\text { glucocorticoid/ } \\
\text { diet/PPI }\end{array}$ \\
\hline 6 & 10 & 8 & $\mathrm{Y}$ & Diet \\
\hline 7 & 5 & 8 & $\mathrm{Y}$ & $\begin{array}{l}\text { Topical } \\
\text { glucocorticoid/diet }\end{array}$ \\
\hline 8 & 3 & 8 & Y & $\begin{array}{l}\text { Topical } \\
\text { glucocorticoid/diet }\end{array}$ \\
\hline 9 & 2 & 18 & $Y$ & $\begin{array}{l}\text { Topical } \\
\text { glucocorticoid }\end{array}$ \\
\hline 10 & 1 & 7 & $\mathrm{~N}$ & $\begin{array}{l}\text { Topical } \\
\text { glucocorticoid/diet }\end{array}$ \\
\hline 11 & 1 & 8 & $Y$ & $\begin{array}{l}\text { Topical } \\
\text { glucocorticoid/diet }\end{array}$ \\
\hline 12 & 0 & 7 & $\mathrm{Y}$ & $\begin{array}{l}\text { Topical } \\
\text { glucocorticoid/PPI }\end{array}$ \\
\hline 13 & 0 & 9 & $Y$ & $\begin{array}{l}\text { Topical } \\
\text { glucocorticoid }\end{array}$ \\
\hline \multicolumn{5}{|l|}{ Control } \\
\hline 1 & 0 & 10 & $\mathrm{~N}$ & None \\
\hline 2 & 0 & 8 & $\mathrm{~N}$ & None \\
\hline 3 & 0 & 11 & $\mathrm{~N}$ & None \\
\hline 4 & 0 & 19 & $Y$ & None \\
\hline 5 & 0 & 3 & $Y$ & None \\
\hline 6 & 0 & 15 & $\mathrm{~N}$ & None \\
\hline 7 & 0 & 8 & $\mathrm{~N}$ & None \\
\hline 8 & 0 & 13 & $Y$ & None \\
\hline 9 & 0 & 11 & $Y$ & None \\
\hline 10 & 0 & 15 & $\mathrm{~N}$ & None \\
\hline 11 & 0 & 16 & $\mathrm{~N}$ & None \\
\hline
\end{tabular}

Table 1. Continued

\begin{tabular}{lccll} 
Diagnosis & $\begin{array}{c}\text { Eosinophils } \\
\text { per HPF }\end{array}$ & Age $(\mathrm{y})$ & Atopy & Treatment \\
\hline GERD & 10 & 17 & Y & PPI \\
1 & 7 & 19 & N & None \\
2 & 5 & 22 & Y & PPI \\
3 & 5 & 7 & Y & None \\
4 & 2 & 15 & Y & PPI \\
5 & 0 & 5 & N & None \\
6 & 0 & 8 & Y & None \\
7 & 0 & 5 & Y & None \\
8 & 0 & 6 & N & PPI \\
9 & 0 & &
\end{tabular}

Description of 38 patients ( 42 biopsies) in four experimental groups: control, eosinophilic esophagitis (EoE), EoE treated, and gastroesophageal reflux disease (GERD). Esophageal histology including eosinophil number and reactive changes (basal zone hyperplasia, rete peg elongation, or spongiosis) were determined by a staff pathologist. Topical glucocorticoids include fluticasone, budesonide, and ciclesonide. HPF, high-power field; $N$, no; PPI, proton pump inhibitor; $Y$, yes.

Expression of hBD1 and hBD3 was significantly reduced in subjects with EoE compared with healthy controls (hBD1-EoE vs. normal: $P<0.0001$; hBD3-EoE vs. normal: $P<0.001)$. No significant differences were measured in defensin expression in GERD subjects compared with healthy controls (hBD1-GERD vs. normal: $P=0.9$; hBD3-GERD vs. normal: $P=0.7$ ) regardless of proton pump inhibitor treatment. GERD subjects had defensin expression levels similar to those of normal subjects and did not have decreased expression as seen in EoE.

To determine the impact of treatment on defensin expression, we next compared hBD1 and hBD3 mRNA levels in mucosal biopsies from subjects with active, untreated EoE with those who had undergone treatment. hBD1 and hBD3 expression in active as well as treated EoE was significantly decreased compared with normal control mucosa (Figure 3). When controlling for inflammation, on the basis of eosinophil numbers in the esophageal mucosa, there was a trend toward restitution of hBD1 and hBD3 levels in message expression, but this did not reach statistical significance.

\section{Immunohistochemical Analysis of hBD Protein}

To determine whether defensin protein patterns were consistent with the above mRNA expression levels, we performed immunohistochemistry analysis of hBD1 and hBD3 from the same subject samples. Normal subject samples revealed diffuse hBD1 and $\mathrm{hBD} 3$ staining of the epithelia with predominance along the luminal border. In contrast, samples from active and treated EoE revealed minimal or no epithelial staining (Figure 4).

To provide a semiquantitative analysis of defensin staining, we used a computer-generated scoring system. Our results demonstrated significantly decreased $\mathrm{hBD} 1$ and $\mathrm{hBD} 3$ mean intensity scores in active and treated EoE samples compared with normal control mucosa (hBD1: 12.5 vs. $16.6, P<0.05$, EoE active vs. normal; 10.1 vs. $16.6, P<0.01$, EoE treated vs. normal and hBD3: 12.3 vs. 16.4, $P<0.05$, EoE active vs. normal; 


\section{Articles $\mid$ schroeder et al.}
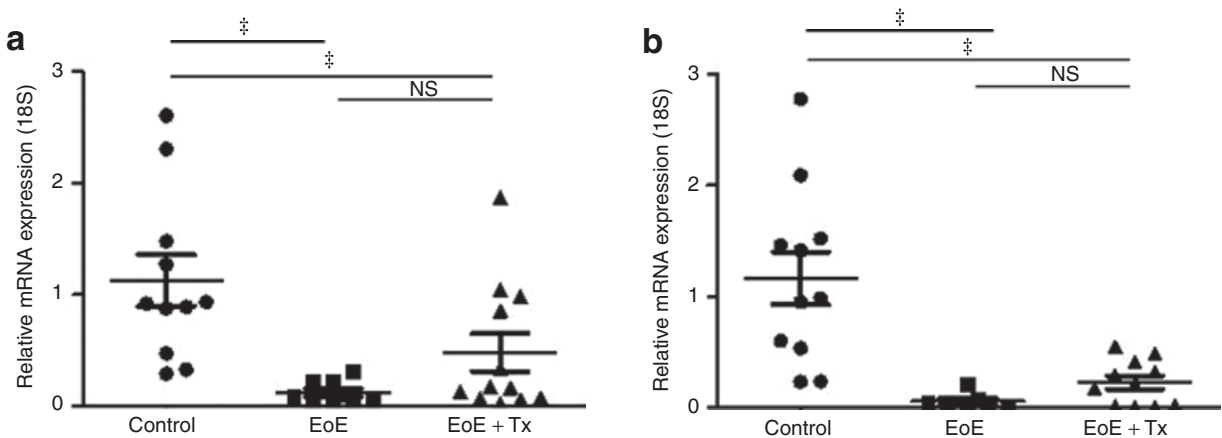

Figure 3. mRNA expression of (a) hBD1and (b) hBD3 in control $(n=11)$, EoE $(n=9)$, and EoE-treated $(n=13)$ human esophageal biopsies, ${ }^{\ddagger} P<0.001$; NS, not significant. EoE, eosinophilic esophagitis; hBD, human $\beta$-defensin.

a
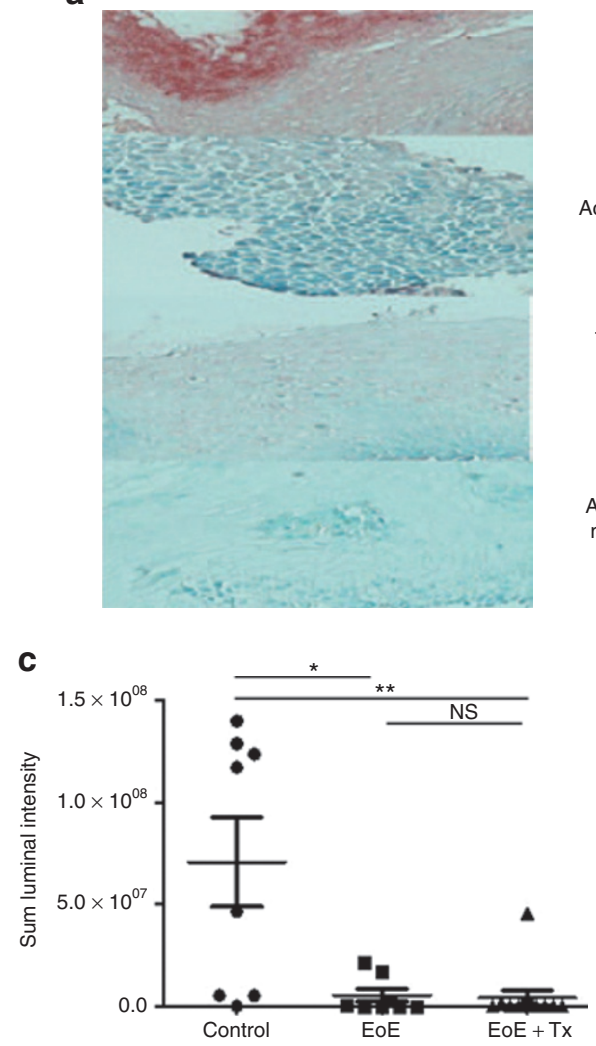

b

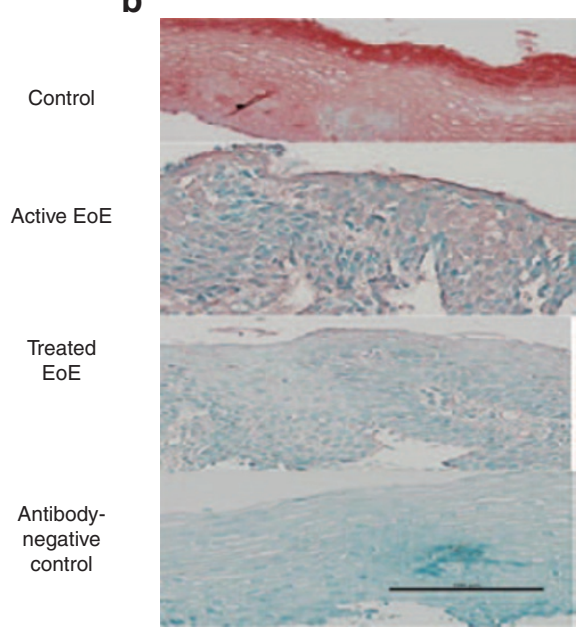

d

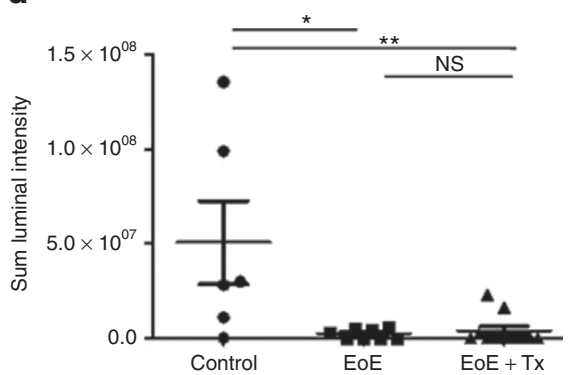

Figure 4. Immunohistochemical staining for (a) hBD1 and (b) hBD3 in esophageal mucosal biopsies from healthy controls compared with EoE and EoE-treated subjects. Magnification is $\times 20$ and scale bar represents $100 \mu \mathrm{m}$ in all images. Staining intensity of the luminal epithelial surface from biopsy samples of healthy controls, EoE, and EoE-treated subjects for (c) hBD1 and (d) hBD3. Intensity staining was measured by microscopy; the graph represents the sum intensity score for each group. ${ }^{*} P<0.05$; ${ }^{*} P<0.01$. EoE, eosinophilic esophagitis.

11.6 vs. $16.4, P<0.01$, EoE treated vs. normal). Figure $4 \mathrm{c}$ and $\mathbf{d}$ illustrates the sum intensity for each group.

Examination of the defensin staining pattern indicated that the predominant staining in normal epithelia occurred within the superficial epithelial cells. To determine whether the hyperplastic basal cells were associated with less hBD1 and $\mathrm{hBD} 3$ protein expression, we correlated defensin staining with basal cell hyperplasia in all subjects' tissues. The degree of basilar cell hyperplasia inversely correlated with the degree of defensin staining, suggesting that the decreased hBD1 and hBD3 expression observed in EoE may be related to the loss of the superficial epithelia rather than decreased epithelial expression of these molecules (Figure 5).

\section{DISCUSSION}

EoE is a chronic esophageal disease of undetermined etiology that bears many similarities to atopic dermatitis. Because a number of lines of evidence suggest that the epithelial barrier may be defective in atopic dermatitis and EoE, we hypothesized that defensins, one form of esophageal innate immunity, would be decreased in EoE, similar to the epithelia in atopic dermatitis. Our novel findings demonstrate that $\mathrm{hBD} 1$ and $\mathrm{hBD} 3$ expression 
a

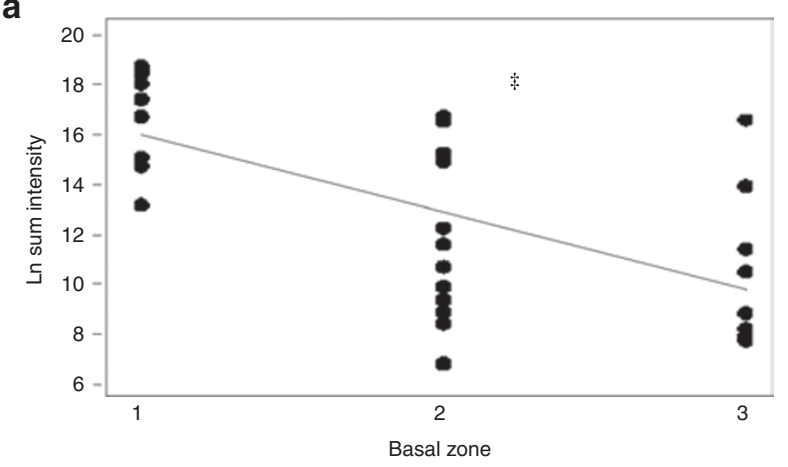

b

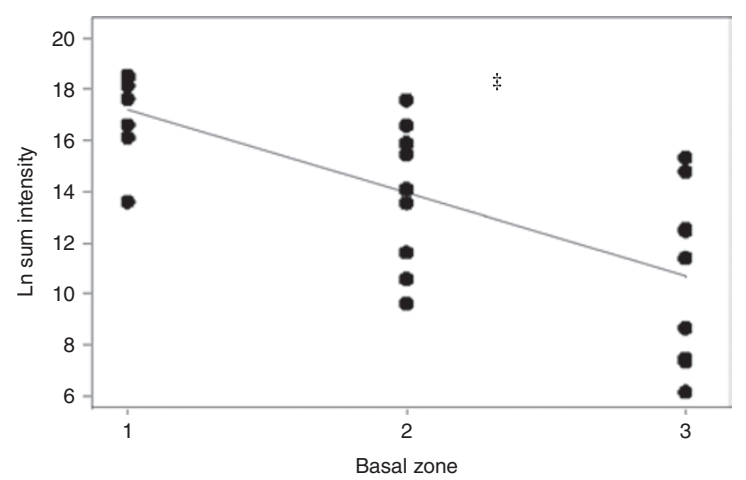

Figure 5. Log-transformed basal epithelial defensin protein expression to degree of basal zone cell hyperplasia for hBD1 and hBD3 in control and all EoE subjects. Spearman correlation for (a) hBD1, $r=0.626,{ }^{\ddagger} P<0.001$, and (b) $\mathrm{hBD} 3, r=0.712,{ }^{\ddagger} P<0.001$. EoE, eosinophilic esophagitis; hBD, human $\beta$-defensin.

is decreased in the esophageal epithelia affected by EoE compared with that from normal and GERD esophageal tissues.

To support a rationale for our studies, we first used immortalized, nonneoplastic esophageal cell lines derived from patients with EoE and GERD and identified decreased expression of hBD1 and hBD3 in EoE compared with GERD cells. In addition, IL-5, a cytokine that plays a key role in the pathogenesis of EoE $(18,21)$, induced the downregulation of hBD1 and hBD3 in EoE but not in GERD cells, suggesting that EoE cells possess different phenotypic alterations than GERD cells. The choice of IL-5 as an agonist was based on the previous findings that demonstrate increased esophageal expression of IL-5 in tissues of patients affected by EoE, increased circulating levels of IL-5 from peripheral eosinophils from patients with EoE, the IL-5 dependency of esophageal eosinophilia in murine models, and the histological impact of anti-IL-5 on reducing eosinophils in therapeutic EoE trials (18-23). Future studies will determine whether other EoE-related cytokines, including IL-13, also alter esophageal defensin expression.

To determine the biological relevance of these findings, we next measured defensin expression in mucosal biopsies from well-defined subjects with active EoE, treated EoE, GERD, and normal esophagus. Although defensin expression did not differ between normal and GERD tissues, significant reductions in both $\mathrm{hBD} 1$ and hBD3 expressions were measured in EoE tissues as compared with the expression in normal tissues. This influence did not seem to depend on the presence or absence of eosinophils because defensin expression was reduced both in treated tissues that showed histological remission and in tissues that contained eosinophils. Together, these results show that the esophageal squamous epithelium from patients with EoE express less hBD1 and hBD3 than controls and suggest that this expression pattern may predispose the patients with EoE to barrier dysfunction.

One intriguing observation is that the pattern of immunohistochemical staining for hBD1 and hBD3 differs in normal compared with inflamed and treated tissues. Normal tissues demonstrated prominent staining throughout the epithelium with predominance at the luminal surface. In contrast, the inflamed tissue showed a diminished staining pattern throughout the epithelium. One possible interpretation of the reduced expression pattern in inflammation is that the majority of defensin expression is contained within the mature cells at the luminal surface and not in the regenerating basal cells that predominate in active EoE. This is supported by the correlation of the hBD1 and hBD3 staining intensity with basal zone hyperplasia score. To date, little is known regarding the specific phenotypes and features of each layer of the stratified esophageal epithelium, but a robust literature supports phenotypic differences within the stratified squamous epithelium of the skin, raising the possibility that this also exists in the esophageal mucosa (24). Future studies that dissect specific cell populations within the esophageal epithelium will better determine the mechanisms for this differential expression pattern.

Defensins are a family of variably cationic 3 - to $5-\mathrm{kDa}$ peptides with a conserved motif of six disulfide-linked cysteines. They display a broad spectrum of antimicrobial activity through micropore formation in the phospholipid bilayer of bacterial membranes $(25,26)$. The production of hBD1 is constitutive, but other defensins are induced by infectious or inflammatory stimuli $(2,4,5)$, and little is known about esophageal defensins $(27,28)$. Atopic dermatitis is a chronic inflammatory disease affecting the squamous epithelium of the skin that is characterized by overexpression of $\mathrm{T}_{\mathrm{H}} 2$ cytokines and epithelial eosinophilia, as well as by a propensity for staphylococcal and herpetic infections. Multiple studies have shown that the increased predisposition to skin infections is caused by decreases in epithelial barrier function (mechanical skin breakdown and abnormal expression of filaggrin) and by dysregulation in dermally expressed defensins (9-12,29-31). Although the microbiome of EoE is not currently characterized, certain immunological features of these two diseases are quite similar, and thus we wondered whether there may be similarities with respect to defensin expression. For instance, in atopic dermatitis, hBD2, hBD3, and LL-37 expression is decreased in skin lesions, and at least one single nucleotide polymorphism in hBD1 has been described (6-14,29-33). In addition, dysregulation of defensins may contribute to the initiation or perpetuation of gastrointestinal diseases. Paneth cell and epithelial defensin expression is diminished in Crohn's and celiac diseases $(3,4,26,34-37)$. Whether these changes in defensin expression reflect decreased epithelial barrier function from underlying inflammation, changes in the luminal microbiome, or gene variations and polymorphisms remains uncertain. 
Decreased defensin expression in EoE could be explained by the overexpression of the $\mathrm{T}_{\mathrm{H}} 2$ cytokine, IL- 5 . In a murine model of EoE, inflammation and remodeling are dependent on the presence of IL-5, and human studies have shown that not only increased levels of this cytokine in patients with EoE, but also therapeutic targeting of IL-5 results in diminished esophageal eosinophilia $(18,19,22,23)$. Our in vitro findings show that IL-5 decreases defensin expression in the EoE cell line, supporting a potential role for IL-5 in decreasing the functional esophageal barrier. IL-5 did not decrease defensin expression in the GERD cell line, suggesting that regulation of defensin expression may differ between the two diseases.

One limitation of our study is that some subjects were treated for EoE or GERD at the time of their esophageal biopsies, and the impact of those treatments on our study results are not known. In the limited number of samples studied, however, no differences were noted in defensin expression based on the treatment received.

We have demonstrated that esophageal defensin expression is decreased in EoE. We speculate that these alterations in innate defense molecules might be a novel pathogenic mechanism for the development of EoE. Alterations in esophageal defensins were specific for EoE when compared with healthy controls and GERD. If confirmed in larger studies, defensin expression may serve as another biomarker helping to distinguish GERD from EoE. Future studies that define regulatory mechanisms for esophageal defensins will be critical to increasing our understanding about the role of defensins in esophagitis and the therapeutic utility of esophageal defensins as a part of the therapeutic armamentarium for EoE.

\section{METHODS}

\section{Cell Culture and Reagents}

Telomerase-immortalized human esophageal epithelial cells were isolated from patients with GERD (NES-G4T) and EoE (EoE1-T) as described previously (38). NES-G4T and EoE1-T (300,000 per well) (passages 87-97 and 86-94, respectively) were grown in 6-well plates (BD Biosciences, San Jose, CA) at $37{ }^{\circ} \mathrm{C}$ in a humidified $5 \%$ $\mathrm{CO}_{2}$ incubator in supplemented keratinocyte basal medium, KBM-2 (Cambrex, East Rutherford, NJ). The cells were incubated with the cytokine IL-5 (R\&D Systems, Minneapolis, MN) at varying concentrations and RNA was isolated.

\section{RNA Extraction and Real-Time Quantitative PCR for Esophageal Epithelial Cells}

Cells were lysed with $\beta$-mercaptoethanol containing RLT cell lysis buffer $(10 \mu \mathrm{l} \beta$-mercaptoethanol per $1 \mathrm{ml}$ RLT buffer) for $5 \mathrm{~min}$ and RNA was harvested using a Qia-shredder and RNeasy kit (Qiagen, Valencia, $\mathrm{CA})$ per the manufacturer's recommendations. Isolated RNA was measured using nanotechnology (Nanodrop; Thermo Fisher Scientific, Wilmington, DE) and equalized to $0.5 \mu$ g per sample. Samples were reverse transcribed using a high-capacity cDNA reverse transcriptase kit (Applied Biosystems, Foster City, CA). Preformulated TaqMan gene expression assays (Applied Biosystems) were utilized to quantify the expression of hBD genes: DEFB1 (Hs00608345_m1) DEFB4 (Hs00823638_m1), DEFB103 (Hs04194486_g1), and 18S (Hs99999901_ s1). Quantitative real-time PCR was performed (AbsoluteBlue Mastermix, Fisher Scientific, Pittsburgh, PA) using 96-well optical plates (Applied Biosystems) on the 7300 RT-PCR platform (Applied Biosystems). All samples were normalized to $18 \mathrm{~S}$ using the $\Delta \Delta C_{\mathrm{T}}$ method of relative quantitation, where $C_{\mathrm{T}}$ was the threshold cycle.

\section{Human Esophageal Tissue Analyses}

Pediatric subjects cared for at the Digestive Health Institute at the Children's Hospital Colorado who underwent endoscopy and mucosal biopsy were recruited for this study. This study was approved by the Colorado Multiple Institutional Review Board. Written informed consent and Health Insurance Portability and Accountability Act authorization were obtained from all participants or from parents or legal guardians of participants aged younger than $18 \mathrm{y}$. Assent was obtained from all participants aged younger than $18 \mathrm{y}$. Indications for procedures included symptoms of dysphagia, reflux, abdominal pain, vomiting, failure to thrive, and evaluation for EoE. Diagnostic criteria used to separate the subjects were as follows: (i) EoE activepatients had symptoms related to esophageal dysfunction, eosinophil counts $\geq 15$ eosinophils per high-power field ( $\times 40$ magnification), and other diseases ruled out; these subjects were not on systemic or topical glucocorticoids, proton pump inhibitors, or dietary elimination at the time of their procedures; (ii) treated EoE-patients had EoE diagnosis previously, and treatments included topical steroids, proton pump inhibitors, and/or dietary elimination(s). The majority of these patients were asymptomatic, but all had repeated endoscopy to evaluate for histologic remission of esophageal eosinophilia; (iii) GERD - patients had symptoms related to esophageal dysfunction and $<15$ eosinophils per high-power field in either the distal or the proximal biopsy specimens and/or abnormal $\mathrm{pH}$ impedance studies; (iv) control subjects-patients had symptoms necessitating an endoscopy, were not taking medications, and had normal esophageal biopsies. Subject characteristics are listed in Table 1. One set of esophageal biopsies was placed in $10 \%$ buffered formalin for histopathologic analysis. Another set of esophageal biopsies was snap-frozen and stored at $-80{ }^{\circ} \mathrm{C}$ for batch analysis as described below.

RNA Extraction and Real-Time Quantitative PCR of Human Tissues Biopsy specimens were homogenized (Fisher Scientific) and RNA was isolated using an RNeasy kit (Qiagen) according to the manufacturer's recommendations. RNA was equalized to $0.05 \mu \mathrm{g}$ per sample. The same isolation and analytical methods used for in vitro studies above were used for human tissues.

\section{Immunohistochemistry of Human Esophageal Tissues}

Formalin-fixed paraffin-embedded samples were used for these studies. Patients undergoing endoscopy had one biopsy collected for RNA analysis and another clinical biopsy for histology. Five-micrometer sections were subjected to immunohistochemical staining as previously described $(39,40)$ for hBD1 and hBD3. Briefly, slides were baked and rehydrated in serial xylene and ethanol concentrations, equilibrated in $1 \times$ phosphate-buffered saline, quenched with $3 \%$ $\mathrm{H}_{2} \mathrm{O}_{2}$ for $20 \mathrm{~min}$, and blocked with $20 \%$ normal goat serum for $1 \mathrm{~h}$ at room temperature. Primary antibodies for hBD1 and hBD3 (Phoenix Pharmaceuticals, Burlingame, CA) were used at a concentration of 1:500 diluted in phosphate-buffered saline and incubated overnight at $4{ }^{\circ} \mathrm{C}$. Slides were washed with $1 \times$ phosphate-buffered saline, blocked with avidin/biotin (Vector, Burlingame, CA), incubated with secondary biotinylated antibody (VECTASTAIN Elite ABC system; Vector) for $1 \mathrm{~h}$ at room temperature, and developed with permanent red (Dako North America, Carpinteria, CA).

\section{Protein Analysis}

Slides were coded and remained blind through the analysis. hBD1 and hBD3 immunostaining intensity was graded according to the following protocol. A standardized region of interest was predetermined as $3,000 \mu \mathrm{m}^{2}$. This region of interest sample size was selected to control for bias and allowed for repetitive samplings from a single specimen to result in data with low variance. For each section $(\times 20$ high-power field), a region of interest containing contiguous staining, including both luminal and basal epithelia, was selected. Intensity was captured from a $3,000 \mu \mathrm{m}^{2}$ area from both the basal and the luminal sides of the section, calculated relative to the area, and recorded using the referenced imaging software (Nikon; Nikon Instruments, Melville, NY). Separate intensity scores were assigned for luminal and basal epithelia using the standardized region of interest for each site. Sum luminal 
intensity scores were then compared between different experimental groups (Figure 4).

Basal intensity scores were correlated to the degree of basal zone hyperplasia. Basal zone hyperplasia was scored as 1,2 , or 3 , where 1 = normal basal epithelium (2-4 cell layers thick), 2 = moderate basal epithelial hyperplasia (up to half of the biopsy being basal epithelium), and 3 = severe basal epithelial cell hyperplasia (up to three-fourths to full-thickness changes). Each tissue section was scored independently by three investigators (S.S., S.F., and R.H.) for the degree of basal zone hyperplasia.

\section{Statistical Analysis}

SAS1 9.2 and Prism (SAS Institute, Cary, NC) were used for statistical analysis. Defensin expression from cell culture experiments was compared by two-sample $t$-test. Human defensins were compared across groups using one-way ANOVA and are represented as standard error in the figures. Protein from luminal and basal epithelium staining was not normally distributed; logarithmic transformation to the natural base was applied to the data. Luminal intensity graphs are presented in original scale, however. Spearman's correlation coefficient $(r)$ was used to assess the correlations between defensin protein and basal epithelial hyperplasia.

\section{ACKNOWLEDGMENTS}

We thank Caleb Kelly for his technical support with in vitro experiments. We thank the physicians (Robert Kramer, Edward Hoffenberg, Edwin Liu, Edwin de Zoeten, Shikha Sundaram, Cara Mack, Michael Narkewicz, Ronald Sokol, Jason Soden, Deborah Neigut, David Brumbaugh, and Christine Waasdorp Hurtado), nurses (Tamela Armstrong and Jo Anne Newton), and technical staff (Bill Marcovich) who contributed to this work by helping to collect samples and enrolling subjects. We are grateful to our patients and families who consented to be a part of this study.

\section{STATEMENT OF FINANCIAL SUPPORT}

The authors recognize the support of Research Electronic Data Capture for the subjects' database supported by the National Center for Research Resources and the National Center for Advancing Translational Sciences, National Institutes of Health (NIH); Colorado CTSI grants UL1 RR025780 (to G.T.F.) and UL1 TR000154 (to G.T.F.); NIH grant T32 DK067009 (to S.S.); and the Shell, Mandell, Savoie, Boyd, and Bitsoff families.

The contents are the authors' sole responsibility and do not necessarily represent official $\mathrm{NIH}$ views.

Disclosure: The authors declare no conflict of interest.

\section{REFERENCES}

1. Canny G, Levy O, Furuta GT, et al. Lipid mediator-induced expression of bactericidal/ permeability-increasing protein (BPI) in human mucosal epithelia. Proc Natl Acad Sci USA 2002;99:3902-7.

2. Ganz T. Defensins and host defense. Science 1999;286:420-1.

3. Ouellete AJ. Defensin-mediated innate immunity in the small intestine. Best Pract Res Clin Gastroenterol 2004;18:405-12.

4. Wehkamp J, Harder J, Weichenthal M, et al. Inducible and constitutive beta-defensins are differentially expressed in Crohn's disease and ulcerative colitis. Inflamm Bowel Dis 2003;9:215-23.

5. Zanger P, Holzer J, Schleucher R, Scherbaum H, Schittek B, Gabrysch S. Severity of Staphylococcus aureus infection of the skin is associated with inducibility of human beta-defensin 3 but not human beta-defensin 2 . Infect Immun 2010;78:3112-7.

6. O'Neil DA, Porter EM, Elewaut D, et al. Expression and regulation of the human beta-defensins hBD-1 and hBD-2 in intestinal epithelium. J Immunol 1999;163:6718-24.

7. Nomura I, Goleva E, Howell MD, et al. Cytokine milieu of atopic dermatitis, as compared to psoriasis, skin prevents induction of innate immune response genes. J Immunol 2003;171:3262-9.

8. Nomura I, Gao B, Boguniewicz M, Darst MA, Travers JB, Leung DY. Distinct patterns of gene expression in the skin lesions of atopic dermatitis and psoriasis: a gene microarray analysis. J Allergy Clin Immunol 2003; 112:1195-202.
9. Ong PY, Ohtake T, Brandt C, et al. Endogenous antimicrobial peptides and skin infections in atopic dermatitis. N Engl J Med 2002;347:1151-60.

10. Howell MD, Gallo RL, Boguniewicz M, et al. Cytokine milieu of atopic dermatitis skin subverts the innate immune response to vaccinia virus. Immunity 2006;24:341-8.

11. Howell MD, Kim BE, Gao P, et al. Cytokine modulation of atopic dermatitis filaggrin skin expression. J Allergy Clin Immunol 2007;120:150-5.

12. Howell MD, Wollenberg A, Gallo RL, et al. Cathelicidin deficiency predisposes to eczema herpeticum. J Allergy Clin Immunol 2006;117:836-41.

13. Prado-Montes de Oca E, Garcia-Vargas A, Lozano-Inocencio R, et al. Association of beta-defensin 1 single nucleotide polymorphisms with atopic dermatitis. Int Arch Allergy Immunol 2007;143:211-8.

14. Mohamed HG, Abbas A, El-Kabarity RH, Diab HM. Association of betadefensin 1 single nucleotide polymorphism with atopic dermatitis. Egypt J Immunol 2009;16:125-38.

15. Cassell H, Mukkada V, Woodruff SA, et al. Atopy in children with eosinophilic esophagitis (EoE) and gastroesophageal reflux disease (GERD). J Food Allergy 2012;1:5-11.

16. Liacouras CA, Furuta GT, Hirano I, et al. Eosinophilic esophagitis: updated consensus recommendations for children and adults. J Allergy Clin Immunol 2011;128:3-20.e6; quiz 21-2.

17. Rothenberg ME. Biology and treatment of eosinophilic esophagitis. Gastroenterology 2009;137:1238-49.

18. Straumann A, Bauer M, Fischer B, Blaser K, Simon HU. Idiopathic eosinophilic esophagitis is associated with a $\mathrm{T}(\mathrm{H}) 2$-type allergic inflammatory response. J Allergy Clin Immunol 2001;108:954-61.

19. Lucendo AJ, De Rezende L, Comas C, Caballero T, Bellón T. Treatment with topical steroids downregulates IL-5, eotaxin-1/CCL11, and eotaxin-3/ CCL26 gene expression in eosinophilic esophagitis. Am J Gastroenterol 2008; 103:2184-93.

20. Blanchard C, Stucke EM, Rodriguez-Jimenez B, et al. A striking local esophageal cytokine expression profile in eosinophilic esophagitis. J Allergy Clin Immunol 2011;127:208-17, 217.e1-7.

21. Mishra A, Wang M, Pemmaraju VR, et al. Esophageal remodeling develops as a consequence of tissue specific IL-5-induced eosinophilia. Gastroenterology 2008;134:204-14.

22. Straumann A, Kristl J, Conus S, et al. Cytokine expression in healthy and inflamed mucosa: probing the role of eosinophils in the digestive tract. Inflamm Bowel Dis 2005;11:720-6.

23. Straumann A, Conus S, Grzonka P, et al. Anti-interleukin-5 antibody treatment (mepolizumab) in active eosinophilic oesophagitis: a randomised, placebo-controlled, double-blind trial. Gut 2010;59:21-30.

24. Ghadilly R. 25 years of epidermal stem cell research. J Invest Dermatol 2012;123:797-810.

25. Zasloff M. Antibiotic peptides as mediators of innate immunity. Curr Opin Immunol 1992;4:3-7.

26. Wehkamp J, Stange EF, Fellermann K. Defensin-immunology in inflammatory bowel disease. Gastroenterol Clin Biol 2009;33 Suppl 3: S137-44.

27. Hosaka Y, Koslowski M, Nuding S, et al. Antimicrobial host defense in the upper gastrointestinal tract. Eur J Gastroenterol Hepatol 2008;20:1151-8.

28. Kiehne K, Brunke G, Meyer D, Harder J, Herzig KH. Oesophageal defensin expression during Candida infection and reflux disease. Scand J Gastroenterol 2005;40:501-7.

29. Howell MD, Fairchild HR, Kim BE, et al. Th2 cytokines act on S100/ A11 to downregulate keratinocyte differentiation. J Invest Dermatol 2008;128:2248-58.

30. Wollenberg A, Räwer HC, Schauber J. Innate immunity in atopic dermatitis. Clin Rev Allergy Immunol 2011;41:272-81.

31. Kim BE, Leung DY. Epidermal barrier in atopic dermatitis. Allergy Asthma Immunol Res 2012;4:12-6.

32. Albanesi C, Fairchild HR, Madonna S, et al. IL-4 and IL-13 negatively regulate TNF-alpha- and IFN-gamma-induced beta-defensin expression through STAT-6, suppressor of cytokine signaling (SOCS)-1, and SOCS-3. J Immunol 2007;179:984-92.

33. Howell MD, Boguniewicz M, Pastore S, et al. Mechanism of HBD-3 deficiency in atopic dermatitis. Clin Immunol 2006;121:332-8. 


\section{Articles $\mid$ schroeder et al.}

34. Wehkamp J, Salzman NH, Porter E, et al. Reduced Paneth cell alpha-defensins in ileal Crohn's disease. Proc Natl Acad Sci USA 2005;102:18129-34.

35. Simms LA, Doecke JD, Walsh MD, Huang N, Fowler EV, Radford-Smith GL. Reduced alpha-defensin expression is associated with inflammation and not NOD2 mutation status in ileal Crohn's disease. Gut 2008;57:90310.

36. Fellermann K, Stange DE, Schaeffeler E, et al. A chromosome 8 gene-cluster polymorphism with low human beta-defensin 2 gene copy number predisposes to Crohn disease of the colon. Am J Hum Genet 2006;79:439-48.

37. Vordenbäumen S, Pilic D, Otte JM, Schmitz F, Schmidt-Choudhury A. Defensin-mRNA expression in the upper gastrointestinal tract is modu- lated in children with celiac disease and Helicobacter pylori-positive gastritis. J Pediatr Gastroenterol Nutr 2010;50:596-600.

38. Jaiswal KR, Morales CP, Feagins LA, et al. Characterization of telomeraseimmortalized, non-neoplastic, human Barrett's cell line (BAR-T). Dis Esophagus 2007;20:256-64.

39. Harder J, Bartels J, Christophers E, Schroder JM. Isolation and characterization of human beta -defensin-3, a novel human inducible peptide antibiotic. J Biol Chem 2001;276:5707-13.

40. Isomoto $\mathrm{H}$, Mukae $\mathrm{H}$, Ishimoto $\mathrm{H}$, et al. High concentrations of human beta-defensin 2 in gastric juice of patients with Helicobacter pylori infection. World J Gastroenterol 2005;11:4782-7. 